\title{
Syntone Chemistry. Theoretical Study on the Formation of Cysteine, Aspartic Acid, Asparagine and Threonine
}

\author{
GHEORGHE SURPATEANU ${ }^{1}$, ILEANA DENISA NISTOR ${ }^{2 *}$, ANA-MARIA GEORGESCU ${ }^{2}$, \\ NECULAI CATALIN LUNGU ${ }^{3}$ \\ ${ }^{1}$ Academy of Romanian Scientists (AOSR), 54 Splaiul Independetei, 050094, Bucharest, Romania \\ ${ }^{2}$ Vasile Alecsandri University of Bacău, Department of Chemical and Food Engineering, 157 Calea Marasesti Str., 600115, \\ Bacau, Romania \\ ${ }^{3}$ Al. I. Cuza University of Iasi, Faculty of Chemistry, Department of Organic Chemistry and Biochemistry, 11 Carol I, \\ 700506, Iasi, Romania
}

\begin{abstract}
In this paper is presented a theoretical study of chemical reactivity on the formation of four proteinogenic amino acids: cysteine, aspartic acid, asparagine and threonine. According to a theoretical model based on three syntons: methylene, nitrene and carbon monoxide at low temperatures, aziridinone would be formed first. This one, with methylene and carbon monoxide forms further the precursors intermediates of these four proteinogenic amino acids. Finally, the precursors in reaction with water, a key component of the primary atmosphere, lead to amino acids specified above. The study is mainly based on quantum mechanical calculations, B88-LYP DFT. Methylaziridonil, aziridonilacetyl and ethylaziridonil radicals should be formed at low temperature, which finally in reaction with water will form cysteine, aspartic acid, asparagine and threonine.
\end{abstract}

Keywords: methylene, nitrene, carbon monoxide, aziridinone, methylaziridinone, ethylaziridinone

\section{Introduction}

In previous papers $[1,2]$, we proposed a model for the formation of the first proteinogenic amino acids. At the basis of these amino acids formation would be three syntones: methylene, nitrenes and carbon monoxide.

In a first step, these syntons at low temperature, in nitrogen, form aziridinone. This one, always with the three syntons whould form amino acids precursors with modified aziridinone structures. The latter, by copolymerization, would form polypeptide chains. The complex mixture of proteinogenic amino acid precursors and their corresponding polypeptides, in contact with the components of the primary atmosphere [3-12]: water, ammonia, methane, carbon dioxide and hydrogen sulfide form at the same time the proteinogenic amino acids and the corresponding polypeptides.

It was considered that all reactions after which the derivative precursors of aziridinone would get, at low temperatures, would form only by reactions resulting after the photochemical reactions model [13], it means that in their way from initial states to final states we would have to do only with a decreasing in energies of involved reaction systems [14-17]. In more drastically thermodynamic conditions, reactions between precursors and primary atmospheric components would be produced. Normally, these may involve transition states of high energy that would require more or less important activations.

In a previous paper [18] we presented reactions involved in the formation of three proteinogenic amino acids with relatively simple structures: glycine, alanine and serine. This is a theoretical study of chemical reactivity in the two thermodynamic contexts previously suggested.

\footnotetext{
*email:dnistor@ub.ro
} 
In this paper we extend the reactivity studies on the next four proteinogenic amino acids: cysteine, aspartic acid, asparagine and threonine. It is time to remember that choosing proteinogenic amino acids sequence, in our studies is defined according to two structural parameters defined in paper [1]: complex structural factor $\left(\mathrm{F}_{\mathrm{e}}\right)$ and the participation coefficient in the formation of polypeptide chains $\left(\mathrm{C}_{\mathrm{p}}\right)$.

\section{General procedure}

The used processes, thermodynamic aspects and reactions involved in the formation of cysteine, aspartic acid, asparagine and serine are presented in this chapter.

The structures of all molecular systems involved in this study were optimized by the sequential using of the following methods: MM3, AM1 and DGauss, B88-LYP [19]. Enthalpies of formation and free energies were calculated through B88-LYP method. The structures of each point have been optimized to obtain the reaction pathways. Transition states have been imagined, from which, the reaction pathways to reactants and to reaction products have been established. At the end, the entire reaction pathway has been simulated. High accuracy was been kept in all calculations.

\section{Results and discussions}

\section{Thermodynamics}

In Table 1 are presented enthalpies of formation $\Delta \mathrm{E}$ (u.a.) of all molecular systems involved in the formation of cysteine, aspartic acid, asparagine and threonine. There are mentioned in order the synthons, primary atmospheric components, proteinogenic amino acids which are taken into account, intermediates with neutral molecular structure and finally the intermediates with radical molecular structures involved in the formation of these four proteinogenic amino acids.

It is worth mentioning some important things for this study. The first aspect is that the aziridinonic cycle in all structures involved shows that iminic nitrogen is paramount, i.e. the hydrogen atom occupies an exocyclic position. The second thing that must be underlined concerns the threonine. Its optimizing took into account the S.D. diastereoisomer that is found in protein structures [20,21].

Enthalpies of formation shown in Table 1 were used to calculate the enthalpies of reaction, respectively the calculation of the free energies, that will be developed in the next section.

Table 1. Entalpies of formation $\Delta \mathrm{E}$ (a.u.)

\begin{tabular}{|c|c|c|c|c|}
\hline No. & Molecular system & Index & Molecular formula & $\Delta \mathrm{E}$ (a.u.) \\
\hline \multirow{4}{*}{1} & \multirow{4}{*}{ Syntones } & 1.1 & $\mathrm{CH}_{2}(\mathrm{~S})$ & -39.11805 \\
\hline & & 1.2 & $\mathrm{CH}_{2}(\mathrm{~T})$ & -39.13453 \\
\hline & & 1.3 & $\mathrm{NH}(\mathrm{T})$ & -55.21622 \\
\hline & & 1.4 & $\mathrm{CO}(\mathrm{T})$ & -113.11143 \\
\hline \multirow{4}{*}{2} & \multirow{4}{*}{$\begin{array}{l}\text { Components of } \\
\text { primary atmosphere }\end{array}$} & 2.1 & $\mathrm{H}_{2} \mathrm{O}$ & -76.42235 \\
\hline & & 2.2 & $\mathrm{NH}_{3}$ & -56.54148 \\
\hline & & 2.3 & $\mathrm{CO}_{2}$ & -188.66661 \\
\hline & & 2.4 & $\mathrm{SH}_{2}$ & -399.34186 \\
\hline \multirow{4}{*}{3} & \multirow{4}{*}{$\begin{array}{l}\text { Proteinogenic amino } \\
\text { acids }\end{array}$} & 3.1 & $\begin{array}{c}\mathrm{CH}_{2}-\mathrm{SH} \\
\mathrm{H}_{2} \mathrm{~N}-\stackrel{\mathrm{C}}{\mathrm{C}}-\mathrm{COOH}\end{array}$ & -721.85922 \\
\hline & & 3.2 & 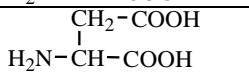 & -512.30191 \\
\hline & & 3.3 & $\begin{array}{c}\mathrm{CH}_{2}-\mathrm{CONH}{ }_{2} \\
\mathrm{H}_{2} \mathrm{~N}-\mathrm{CH}-\mathrm{COOH}\end{array}$ & -492.41296 \\
\hline & & 3.4 & $\begin{array}{l}\mathrm{H}_{3} \mathrm{C}-\mathrm{CH}-\mathrm{OH} \\
\mathrm{H}_{2} \mathrm{~N}-\mathrm{C}-\mathrm{C}-\mathrm{COOH}\end{array}$ & -438.23317 \\
\hline \multirow{4}{*}{4} & \multirow{4}{*}{ Neutral intermediates } & 4.1 & $\begin{array}{c}\mathrm{SH} \quad \mathrm{NH}_{1} \\
\mathrm{H}_{2} \mathrm{C}-\mathrm{HC}-\mathrm{CO}\end{array}$ & -645.38019 \\
\hline & & 4.2 & $\begin{array}{cc}\mathrm{HOOC} & \mathrm{NH}_{1} \\
\mathrm{I}_{2} \mathrm{C} & \stackrel{\mathrm{H}}{\mathrm{C}}-\mathrm{CO}\end{array}$ & -435.82484 \\
\hline & & 4.3 & 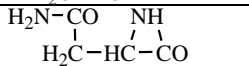 & -415.93782 \\
\hline & & 4.4 & \begin{tabular}{cc}
$\mathrm{HOOC}$ & $\mathrm{NH}$ \\
$\mathrm{I}$ & \multicolumn{1}{l}{} \\
$\mathrm{HO}-\mathrm{HC}-\mathrm{HC}-\mathrm{CO}$
\end{tabular} & -361.75754 \\
\hline
\end{tabular}




\begin{tabular}{|c|c|c|c|c|}
\hline \multirow{9}{*}{5} & \multirow{9}{*}{ Radical intermediates } & 5.1 & $\mathrm{HO}$. & -75.73605 \\
\hline & & 5.2 & HS. & -398.69967 \\
\hline & & 5.3 & $\mathrm{H}_{2} \mathrm{~N} \cdot$ & -55.86838 \\
\hline & & 5.4 & 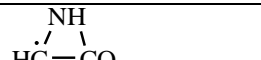 & -207.26284 \\
\hline & & 5.5 & $\begin{array}{c}\mathrm{NH} \\
\mathrm{H}_{2} \dot{\mathrm{C}}-\stackrel{\mathrm{CH}}{\mathrm{C}}-\mathrm{CO}\end{array}$ & -246.56109 \\
\hline & & 5.6 & 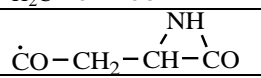 & -359.89507 \\
\hline & & 5.7 & $\begin{array}{c}\mathrm{O}_{\mathrm{O}}-\mathrm{NH}-\mathrm{CH}_{2}-\mathrm{CH}-\mathrm{CO} \\
\dot{\mathrm{O}}\end{array}$ & -435.14949 \\
\hline & & 5.8 & $\begin{array}{c}\stackrel{\mathrm{NH}}{\prime} \\
\mathrm{H}_{2} \dot{\mathrm{C}}-\mathrm{CH}_{2}-\stackrel{\mathrm{CH}}{\mathrm{C}}-\mathrm{CO}\end{array}$ & -285.84542 \\
\hline & & 5.9 & 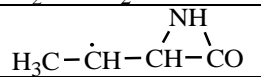 & -285.86164 \\
\hline
\end{tabular}

(S) - singlet; (T) - triplet

\section{Reactions}

Previously [1,2] it was shown that aziridinonil radical may be formed by several reactions involving the different molecular radically systems. We can remember only the reaction between aziridinone and methylene in singlet state.

We must note that in this study we calculated the enthalpies of formation and Gibbs free energies only for reactions apparently without transition state [14-17], which result at low temperatures. For the reactions occurring at contact with atmospheric primary components that may require activations too, reactions which occur at higher temperatures, we have mentioned only the reaction enthalpies.

Another aspect that deserves to emphasize is that the precursors of proteinogenic amino acids with structures of aziridinone radically derivatives together with initial synthones and many other neutral or radical molecular structure compounds meet primary atmospheric components with which are forming the proteinogenic amino acids, among other compounds.

By "other compounds" we mean a large number of chemical compounds known as interstellar compounds [3-12]. In these conditions we can imagine that reactions between radically compounds and primary atmospheric components would form also the radicals such as $\mathrm{HS} \cdot \mathrm{HO} \cdot \mathrm{H}_{2} \mathrm{~N} \cdot$ types. That's why some reactions with these radicals are not totally excluded.

Finally we assume that once the hydroxyl radicals ( $\mathrm{HO} \cdot)$ are formed, they would lead to oxygen in water by means of hydrogen peroxide.

Free energies for the reactions presented in Table 2 are given at two different temperatures, respectively $200 \mathrm{~K}$ and $300 \mathrm{~K}$.

Table 2. Reaction enthalpies ( $\Delta \mathrm{H}$, a.u.) And free energies $(-\Delta \mathrm{G}$, a.u.) at $200 \mathrm{~K}$ and $300 \mathrm{~K}$ in formation of cysteine, aspartic acid, asparagine and threonine

\begin{tabular}{|c|c|c|c|}
\hline No. & Reactions & $\Delta \mathrm{H}$, a.u. & - $\Delta \mathrm{G}$ (a.u.) \\
\hline \multirow{3}{*}{1} & Cysteine & a) -139.65 & \multirow{3}{*}{$\begin{array}{l}\text { a) }-246.519664 \\
-246.530104\end{array}$} \\
\hline & \multirow{2}{*}{ 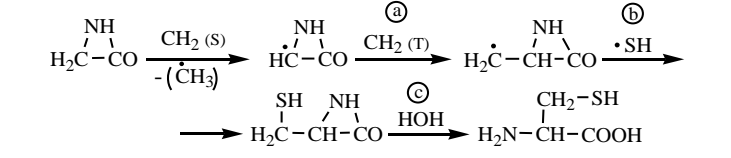 } & b) -75.84 & \\
\hline & & c) -34.49 & \\
\hline \multirow{4}{*}{2} & Aspartic acid & a) -10.03 & \multirow{4}{*}{$\begin{array}{r}\text { a) }-359.830832 \\
-359.841894\end{array}$} \\
\hline & \multirow{3}{*}{ 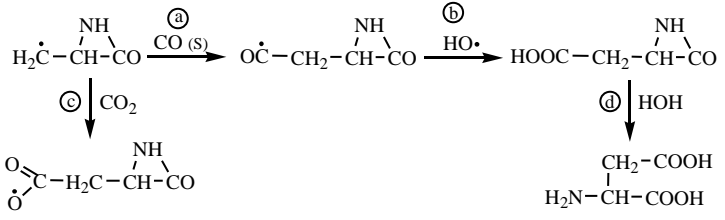 } & b) -121.55 & \\
\hline & & c) +11.42 & \\
\hline & & d) $\quad-34.33$ & \\
\hline
\end{tabular}




\begin{tabular}{|c|c|c|c|}
\hline \multirow[b]{2}{*}{3} & Asparagine & a) -109.41 & \\
\hline & 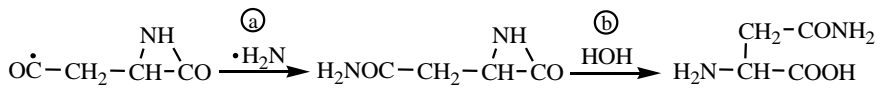 & b) -33.12 & \\
\hline \multirow{4}{*}{4} & Threonine & a) -93.99 & a) -285.773629 \\
\hline & \multirow{3}{*}{ 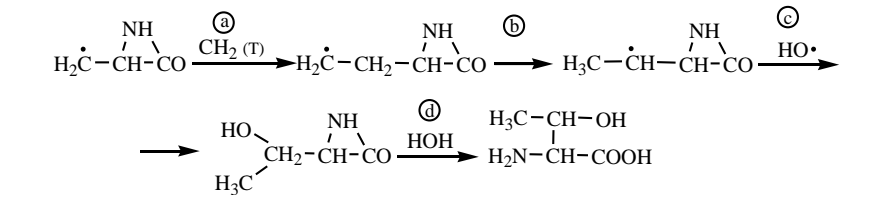 } & b) -4.05 & -285.784443 \\
\hline & & c) -100.30 & b) -285.773592 \\
\hline & & d) $\quad-33.43$ & -285.784393 \\
\hline
\end{tabular}

A careful analysis of reactions in Table 2 allows the selection of those which must occur at low temperatures. These are the following: 1a, 2a, 4a and 4b. Only for these reactions enthalpies of reaction and Gibbs free energies have been calculated. The reaction enthalpies were calculated for the rest of the reactions which occur at the time of contact with the primary atmosphere components.

Concerning the formation of cysteine, this involves a single reaction, $1 \mathrm{a}_{\mathrm{i}}$, that does not require activation, reaction described previously $[1,2]$. In the case of aspartic acid formation at low temperatures it is needed only of aziridinonilacetyl radical formation. This one, further with water forms aziridinonil acetic acid, respectively aspartic acid. We can imagine the formation of a precursor of aspartic acid by reaction between the methylaziridinonil radical and carbon dioxide (reaction 2c). This endothermic reaction is less probable, but not totally excluded.

Concerning the formation of asparagine, it requires at low temperatures only the aziridinonilacetyl radical formation, like in the case of aspartic acid formation.

The study of threonine formation reveals interesting results. Specifically, this requires two reactions $4 \mathrm{a}$ and $4 \mathrm{~b}$, which occur at low temperatures. According to curves alure representing the reaction pathways, only the aziridinoniletil radical formation (reaction 4a) occurs with continuously decreasing energy of the reaction system.

In Figure 1 are given the curves of reaction pathways and in Table 3 are presented the enthalpies of formation values for initial $\left(\Delta \mathrm{E}_{\mathrm{i}}\right)$ and final $\left(\Delta \mathrm{E}_{\mathrm{f}}\right)$ reaction states.

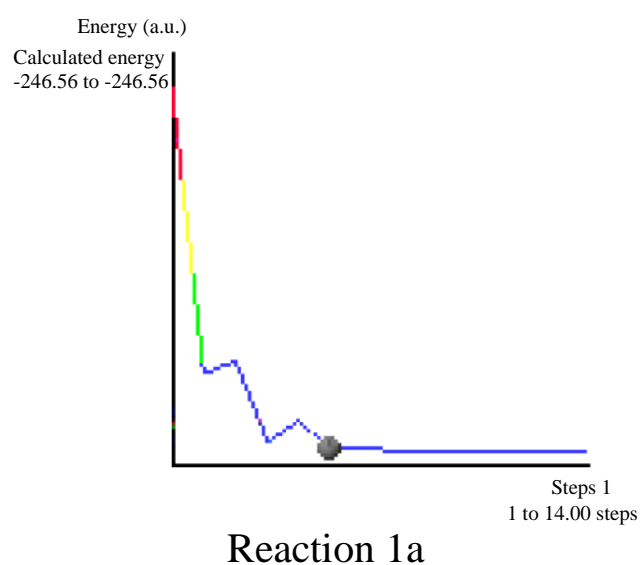

Reaction 1a

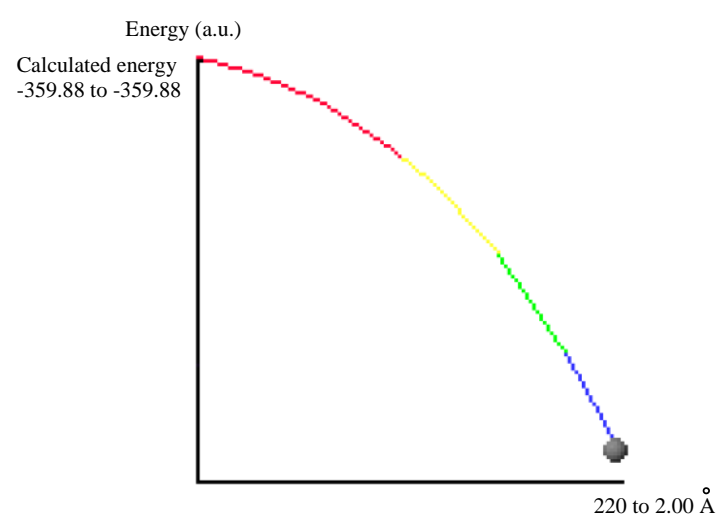

Reaction $2 \mathrm{a}$ 


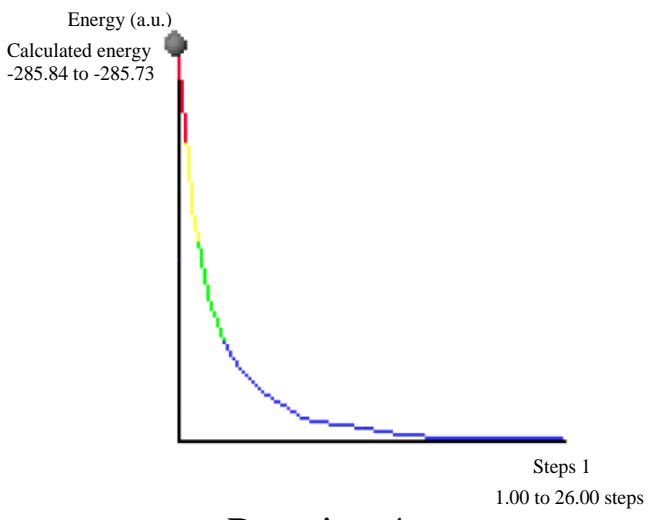

Reaction $4 \mathrm{a}$

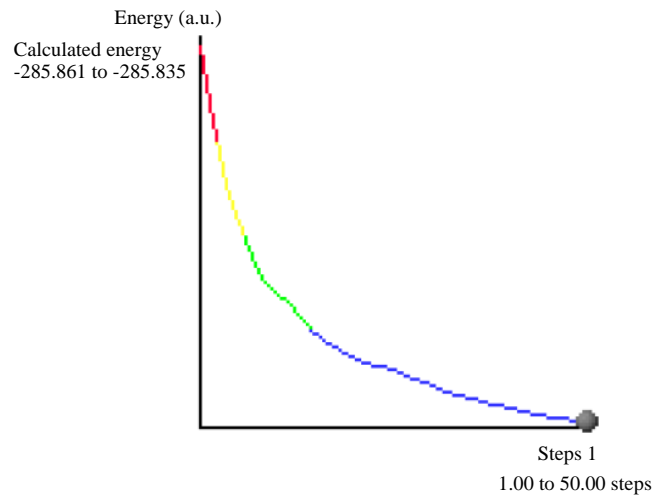

Reaction $4 b$

Figure 1. Curves allure of reaction pathways

Table 3. Initial and final enthalpies ( $\delta \mathrm{E}_{\mathrm{i}}$ and $\delta \mathrm{E}_{\mathrm{f}}$, a.u.)

for reactions at low temperature

\begin{tabular}{|r|c|c|c|}
\hline \multicolumn{1}{c}{$\mathrm{N}$} & $\begin{array}{c}\text { Reactio } \\
\text { ns }\end{array}$ & $\Delta \mathrm{E}_{\mathrm{i}}$ (a.u.) & $\Delta \mathrm{E}_{\mathrm{f}}$ (a.u.) \\
\hline 1 & $1 \mathrm{a}$ & -246.34176 & -246.56109 \\
\hline 2 & $2 \mathrm{a}$ & -359.87908 & -359.89507 \\
\hline 3 & $4 \mathrm{a}$ & -285.69562 & -285.84542 \\
\hline 4 & $4 \mathrm{~b}$ & -285.84542 & -285.86164 \\
\hline
\end{tabular}

In the case of isomerization, the curve $\mathrm{r} 4 \mathrm{~b}$ corresponding to reaction $4 \mathrm{~b}$, represents the passing from the transition to the final state. It seems that the involved isomerization would require activation. Perhaps it is time to mention that by "low temperature" must understand a wide temperature range between liquid nitrogen temperature and ambient temperature. Certainly, in contact with the primary atmosphere components, the temperatures should be close to $0^{\circ} \mathrm{C}$. That's why those estimations related to the temperature at which these changes occur must be considered with very large reserves.

\section{Conclusions}

At the end of this work, several conclusions can be highlighted.

Aziridinone is obtained starting from three synthones: methylene, nitrenes and carbon monoxide at low temperatures.

From aziridinone, in the reaction with methylene and carbon monoxide are obtained four radical precursors: methylaziridonil, aziridonilacetyl and two ethylaziridonil radicals.

Isomerization of two ethylaziridonil radicals requires activation, but we suppose that it can occur at lower temperatures than the ambient temperature. The light presence can be crucial.

Radical precursors in reaction with water, an essential component of primary atmosphere at temperatures much closer to ambient temperature, lead to the formation of: cysteine, aspartic acid, asparagine and threonine.

The quantitative data from this theoretical study were obtained by DFT-B88 LYP calculations.

We will continue our studies until the completion of the proteinogenic amino acids series.

\section{References}

1. SURPATEANU, G., Int. J. Astrobiology, 17, no. 4, 2017, p. 361.

2. SURPATEANU, G., LUNGU, N.C., Rev. Chim., 62(11), 2011, 1107-1110.

3. MILLER, S. I., Science, 117, no. 3046, 1953, p. 528.

4. SCHESINGER, G., MILLER S. L., J. Mol. Evol., 19, no. 5, 1983, p. 376.

5. WINCEL, H., FOKKENS, R. H., NIBBERING, N. M. M., Rapid Commun. Mass Spectrom., 14, no. 3, 2000, p. 135. 
6.EHRENFREUND, P., BERNSTEIN, M. P., DWORKIN, J. P., SANDFORD, S. A., ALLAMANDOLA L. J., Astrophys. J., 550, no. 1, 2001, L95.

7. SORRELL, W. H. , Astrophys. J., 555, no. 2, 2001, L129.

8. BLAGOJEVIC, V., PETRIE, S., BOHME D. K., Mon. Not. R. Astron. Soc., 339, no. 1, 2003 , L7.

9. THADDEUS, P., Phil. Trans. R. Soc. B., 361, no. 1474, 2006, p. 1681.

10. BRACK, A., Chem. Biodivers., 4, no. 4, 2007, p. 665.

11. TAKANO, Y., TAKAHASHI, J., KANEKO, T., MARUMO, K., KOBAYASHI K., Earth Planet. Sci. Lett., 254, no. 1-2, 2007, p. 106.

12. ELSILA, J. E., GLAVIN, D. P., DWORKIN, J. P., Meteorit. Planet. Sci., 44, no. 9, 2009, p. 1323.

13. BAltrusaitis, J., PATTERSON, E., HATCH, C., J. Phys. Chem. A, 116, no. 37, 2012, p. 9331.

14. BERNARDI, F., OLIVUCCI, M., ROBB, M. A., Chem. Soc. Rev., 25, no. 5, 1996, p. 321.

15. Baltrusaitis, J., PATTERSON, E., HATCH, C., J. Phys. Chem. A, 116, no. 37, 2012, p. 9331.

16. SIMS, I. R., SMITH, I. W. M., Ann. Rev. Phys. Chem., 46, 1995, p. 109.

17. JUNG, SE-H., JANG, SU-C., KIM, JIN-W.,KIM, JANG-W., CHOI, JONG-H., J. Phys. Chem. A, 119, no. 49, 2015, p. 11761.

18. SURPATEANU, G., NISTOR, I.D., GEORGESCU, A.M., LUNGU, N.C., Rev. Chim., 70, no. 5, 2019, p. 1707.

19. Cache Worksystem Library version 7.5.0.85, Fujitsu, Poland, 2006.

20. KISUMI, M., KOMATSUBARA, S., CHIBATA, I., J. Biochem., 82, no. 1, 1977, p. 95.

21. WALL, M. A., COLEMAN, D. E., LEE, E., IÑIGUEZ-LLUHI, J. A., POSNER, B. A. GILMAN, A. G., SPRANG S. R., Cell, 83, no. 6, 1995, p. 1047. 